\title{
Development of a laboratory scale air plasma torch and its application to electronic waste treatment
}

\author{
*N. Tippayawong; P. Khongkrapan \\ Department of Mechanical Engineering, Chiang Mai University, Chiang Mai 50200, Thailand \\ Received 5 December 2008; $\quad$ revised 18 April 2009; accepted 15 May 2009; available online 1 June 2009
}

\begin{abstract}
Expansion in electrical and electronic equipment trade has led to significant increase in electronic waste which should be dealt with special priority due to its potential negative impact to the public health and the environment. Thermal plasma technology offers a very promising alternative of hazardous waste treatment for the near future. In this study, a laboratory scale apparatus for generating high temperature plasma flame was presented. Design of a $20 \mathrm{~kW}$ plasma torch system was based on a non transferred direct current arc discharge with air as a medium gas. In this investigation, measurements of temperature distribution were performed. It was shown that high temperature flames can be generated, comparable to those reported in the literature. The gas temperature was found to increase with an increase in power input. The flame temperature was found to further increase from $1210 \mathrm{~K}$ to $1480 \mathrm{~K}$ when a small amount of added fuel gas. Assessment of electronic waste treatment using the air plasma system in a batch operation was also carried out. It was shown that the system was able to convert the electronic waste into combustible gas and inert solid residues. High mass loss rate of bulk electronic waste was demonstrated.
\end{abstract}

Keywords: Arc discharge; Hazardous waste; Plasma burner; Thermal treatment; Waste management

\section{INTRODUCTION}

The production of electrical and electronic equipment is one of the fastest growing businesses in the world. The useful life of consumer electronic products is relatively short and decreasing as a result of rapid changes in equipment features and capabilities. Technological innovation and market expansion are accelerating the replacement of outdated equipment, leading to a significant increase in waste that induces a new environmental challenge. Concerns over environmental issues arising from these electrical and electronic products have led to a number of environmental regulations such as the waste electrical and electronic equipment (WEEE) and restrictions on hazardous substances (RoHS) directives. These directives directly affect the electrical and electronic industries throughout the world (Hsu and $\mathrm{Hu}, 2008$ ). Electronic waste is considered to be one of the priority streams in waste management. Challenges faced by WEEE management are not only consequences of growing quantities of waste, but also the complexity of WEEE (Nnorom and Osibanjo, 2008; Widmer et al., 2005). Electronic waste is loosely applied to consumer

ه *Corresponding Author Email: n.tippayawong@yahoo.com Tel.: +66 5394 4146; Fax: +66 53944145 and business electrical and electronic equipment that is broken, near the end of its useful life or unwanted. It is one of the most complex waste streams because of the wide variety of products from mechanical devices to highly integrated systems and the accelerating technological innovations. Certain components of some electronic products contain materials that render them hazardous. Incineration is normally used for waste destruction and reduction of waste volume (Shekdar, 2009). However, some compounds such as chloride and heavy metals can remain in ash and cause secondary environmental problems. Alternative thermal treatment technology is required for sterilization, as well as volume reduction.

Need for high temperature thermal processing in various applications such as solid waste destruction has led to a rapid growth in the use of plasmas and plasma-based technologies into industry (Bonizzoni and Vassallo, 2002; Chang, 2001; Kogelschatz, 2004; Leal-Quiros, 2004; Pfender, 1999). Hazardous materials may be destroyed by the high-temperature plasma energy under the reducing or the oxidizing condition of plasma gas. Plasma-chemical treatment technology has been used in the highly efficient processes such 
as thermal cracking and oxidation of hazardous wastes (Kim et al., 2003) and gases (Zhu et al., 2008). Plasmas contain highly reactive species, such as electrons, ions and radicals which can enhance chemical reactions. Plasmas can be divided into two categories: thermal plasmas and non-equilibrium plasmas. Thermal plasmas are atmospheric-pressure plasmas characterized by high enthalpy content and temperatures about 2,000-10,000 K. Non-equilibrium plasmas are low pressure plasmas characterized by high electron temperatures and low ion and neutral temperatures. Thermal plasma device or plasma torch produces arc plasma column between two electrodes. There are several types of plasma torches: direct current (DC) arc torch, induction torch and highfrequency capacitive torch (Ganguli and Tarey, 2002; Venkatramani, 2002).

There are a number of researches on treatment of waste using plasma torches. Inaba et al. (1998) developed a laboratory scale, $60 \mathrm{~kW}$ DC arc plasma torch using argon as working gas and applied it to melt fly ash into a glassified slag. Inaba and Iwao (2000) further utilized a plasma torch to treat wastes, and discussed aspects of plasma processes in the destruction and removal of mixed wastes and hazardous wastes. Uhm and Hong (2000) developed a simple model to simulate physics of plasma torch and used the model to investigate an arc plasma system for waste treatment. They found that with oxygen as working gas, very high oxidation rate could be achieved. Wald et al. (2001) presented the use of a pulsed plasma technology to treat hazardous waste and reported higher destruction efficiency than other conventional thermal methods. Kim et al. (2003) applied a $100 \mathrm{~kW}$ DC steam plasma to minimize dioxins and furans from processing of polychlorinated biphenyls (PCB) waste and found that the DC steam plasma process was efficient in decomposing high concentration of PCB and minimizing the toxic byproducts. Park et al. (2005) treated medical waste with a pilot plasma unit and found that the temperature range between 1,450-1,850 K inside the plasma furnace can be attained at a specific power of 1,125-2,100 kW/ $\mathrm{m}^{2}$. Moustakas et al. $(2005 ; 2008)$ reported successful installation and testing of a demonstration $50 \mathrm{~kg} / \mathrm{h}$ pilot plant with plasma vitrification system to treat industrial hazardous waste, as well as further performance optimization. Tendler et al. (2005) presented a review and assessment of the hot temperature discharge physics and processing of the waste, including vitrification, gasification, power generation and environmental advantages. More recently, Hong et al. (2006) and Bang et al. (2006) developed microwave plasma torches to produce high temperature plasma flame. They reported a boost in flame temperature with hydrocarbon fuel injection that can be used for bulk treatment of waste. The latest review on thermal plasma technology to date was given by Gomez et al. (2009), where a comprehensive analysis of available literature on the current status of waste treatment using thermal plasma technology was presented.

From existing literature, it was clearly shown that plasma treatment was well established for common waste streams and there were modest amounts of works regarding hazardous waste. To the authors' knowledge, investigation on electronic waste treatment with plasma is still very rare. Furthermore, most studies focused on using inert gases or steam as working gasses. Due to economic reason, use of the cheapest gas (the air) appears most practical. Therefore, the present investigation is an attempt to lessen this gap. In this study, a $20 \mathrm{~kW}$ atmospheric air plasma using DC discharge was developed for a laboratory study. The objective was to investigate DC plasma characteristics and utilize it to process electronic waste.

\section{MATERIALS AND METHODS}

Fig. 1 shows schematically design of a DC plasma torch, consisting of a steel rod cathode and an air cooled anode, shaped in the form of nozzle. The two electrodes are separated by an insulator which has an inlet for plasma gas. When compressed air is introduced thru the electrode gap and a DC arc is established between the electrodes, the plasma arc is emerged from the nozzle resulting in a high temperature, high velocity plasma flame. Electromagnetic forces from magnetic coil and gas flow act to constrict the arc column. The body of the torch was designed such that there are cooling chambers for cathode and anode. The torch was coupled to the main power supply and operated in a non-transferred arc mode. Air or a mixture of air and other gases can be used as medium gas. Liquefied petroleum gas (LPG) can be injected to air plasma via connecting pipe. For the preliminary design, the operation ranges of power and air flow of the plasma 
torch were limited to $12-20 \mathrm{~kW}$ and $300 \mathrm{l} \mathrm{pm}$, respectively. Temperatures were measured at different positions of the flame by a type $\mathrm{K}$ thermocouple. These locations were linearly 10 or $20 \mathrm{~mm}$ apart in axial direction and 5 or $10 \mathrm{~mm}$ apart in radial direction of the main flame column, starting from the torch exit.
A schematic diagram of a laboratory scale, plasma furnace for treatment of electronic waste is shown in Fig. 2. It was equipped with the air plasma torch, a refractory-lined circular reactor and a gas flare prior to exhaust. The dimensions of the reactor were about $100 \mathrm{~mm}$ in diameter and $200 \mathrm{~mm}$ long. Old central

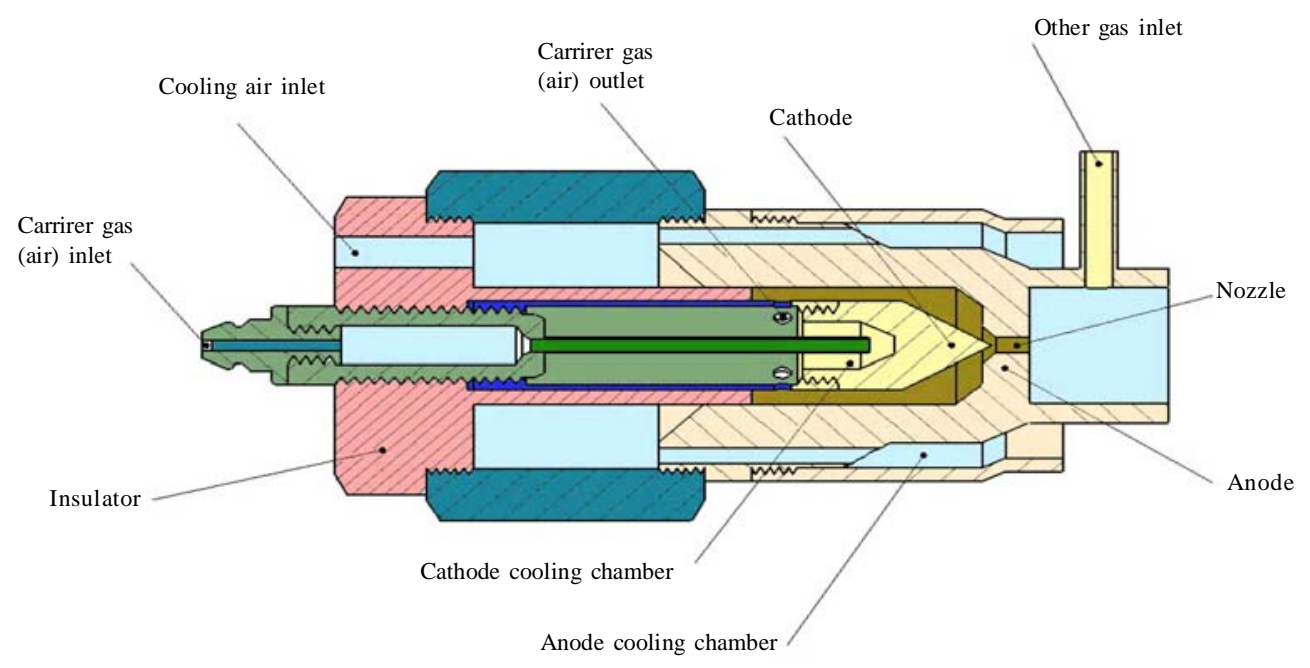

Fig. 1: Schematic drawing of a DC plasma torch

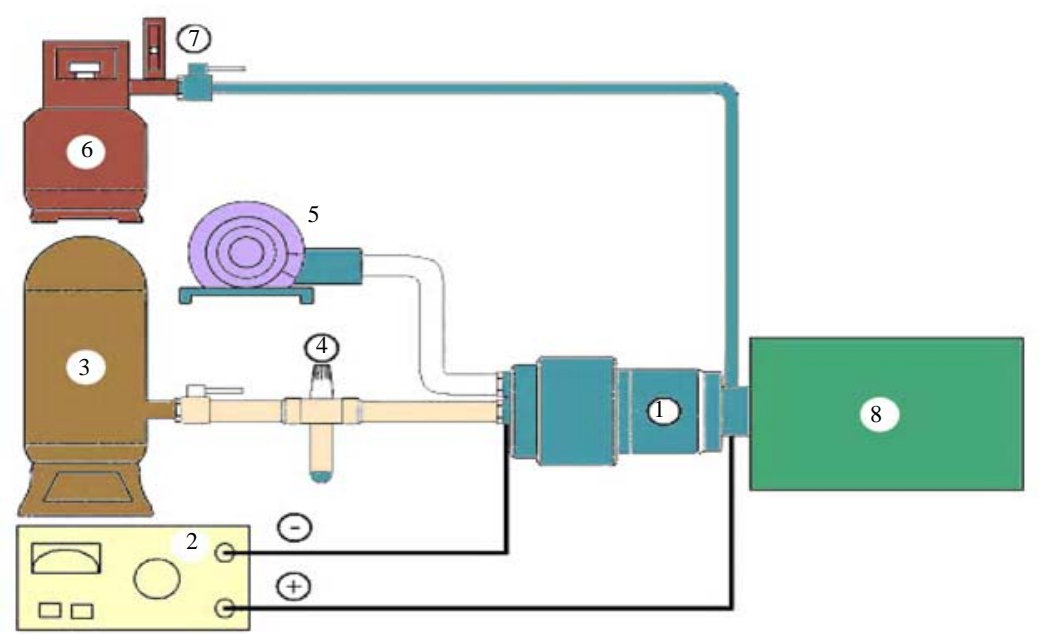

Fig. 2: Schematic diagram of a plasma process for treatment of electronic waste; (1) plasma torch, (2) DC power supply, (3) air tank, (4) air flow regulator, (5) blower for cooling air, (6) LPG tank, (7) gas flow regulator, (8) furnace module 
processing unit (CPU) board was used as representative electronic waste. The waste of $0.2 \mathrm{~kg}$ can be batch fed into the reactor where rate of reduction in mass and the reactor temperature were monitored. The research work was performed at Chiang Mai University between October 2007 and October 2008.

\section{RESULTS AND DISCUSSION}

\section{Plasma torch performance}

From simple visual observation, a pure air plasma flame showed milky white lights with blush-like, turbulent flame tip at normal operation. This was the expected character of high ionized plasma density in air discharge. Plasmas flame exhibited marginal fluctuation in length with an observed average length of about $100 \mathrm{~mm}$. The radius of the plasma was observed to be about $3 \mathrm{~mm}$. The radius was found to have a slight increase as the power input increased. With addition of small amount of LPG, it was observed that the color of plasma flame changed to bright, light blue-ish. This may be attributed to the presence of unstable $\mathrm{CH}$ radicals in the plasma. Nonetheless, the flame dimension did not show any significant change. Figs. 3 and 4 show temperature profiles of the air plasma flame. Temperature distributions along the axial and radial directions at different power ratings were illustrated. The results showed that the gas temperature increased with an increase in power input. This finding was in similar tendency to that reported by Inaba et al. (1998). For the same input power, the gas temperature showed a decline along axial length and away from the flame center. The maximum temperatures of the air plasma flame at the center of the flame exit were between 980 and 1, $210 \mathrm{~K}$. This is

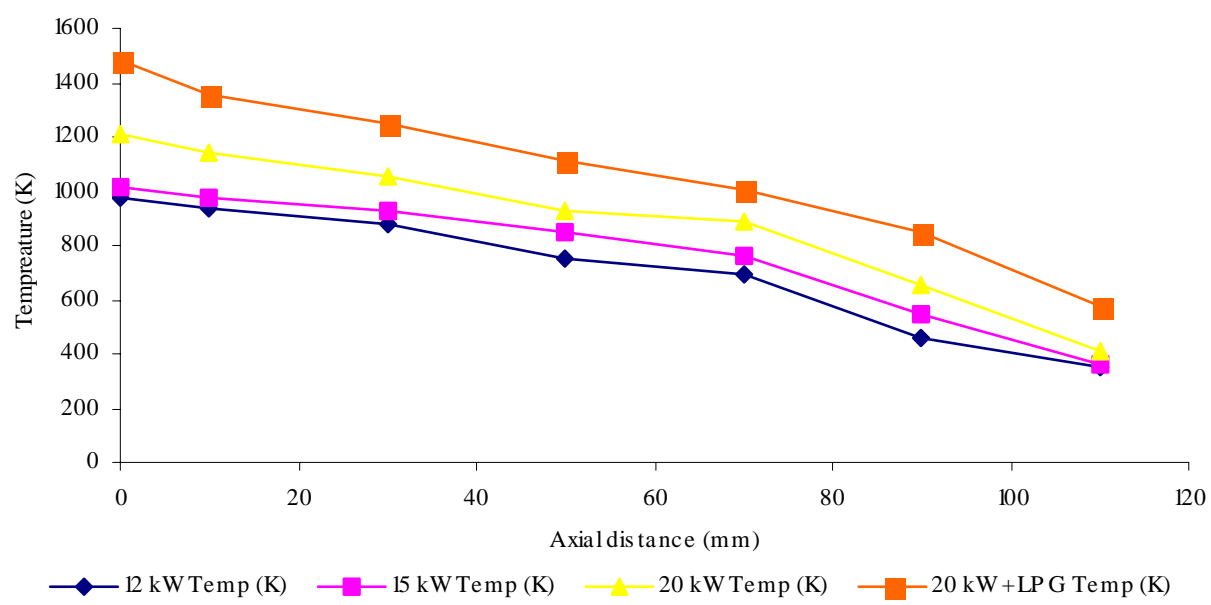

Fig. 3: Axial distribution of plasma flame temperature

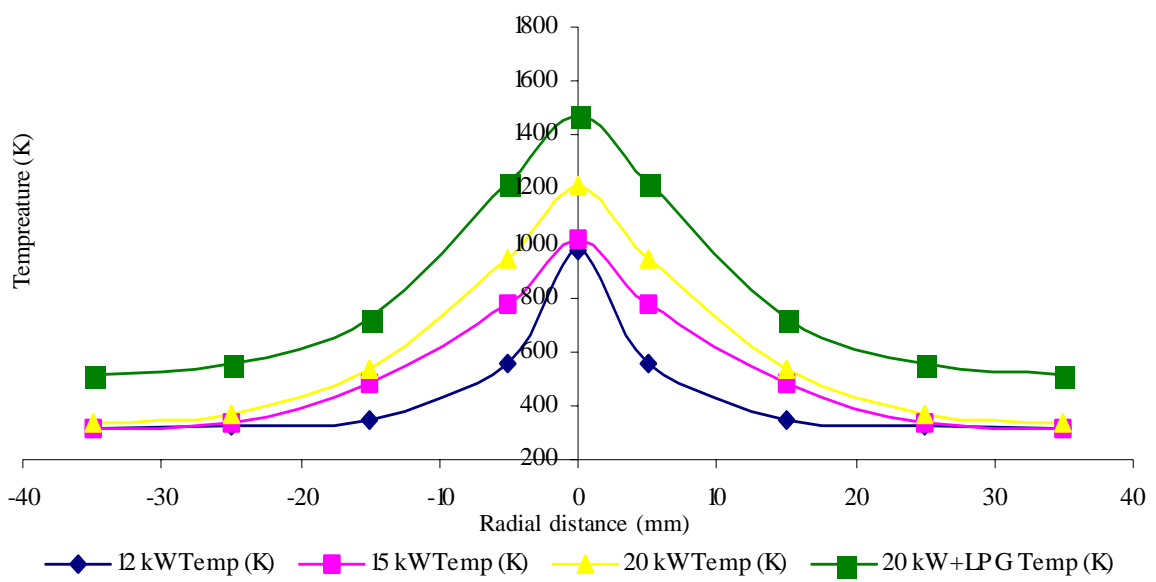

Fig. 4: Radial distribution of plasma flame temperature 
significantly higher than $550 \mathrm{~K}$, reported by Hong et al. (2006), but similar to $1,173-1,773 \mathrm{~K}$, reported by Tang and Huang (2005) for temperatures of air/nitrogen plasma generated by microwave source. However, when 51 pm LPG was injected as a fuel into the air plasma flame, the maximum gas temperature measured by a thermocouple drastically raised to $1480 \mathrm{~K}$.

It should be noted that the fuel-air mixture of the LPG was only $1.63 \%$ which was well below the lean side of its flammability limit, defined as the boundary composition of the fuel-air mixture beyond which gas is incapable of flame propagation (Mishra and Rahman, 2003). Nonetheless, an increase in gas temperature after LPG addition may be resulted from exothermic chemical reaction accomplished by high temperature and high radical density of the plasma flame, similar to that observed by Bang et al. (2006). From the preliminary experimental data, the air plasma burner may be used for bulk thermal treatment of waste.

\section{Destruction of electronic waste}

Electronic waste can be processed using high temperature air plasma torch operated at $20 \mathrm{~kW}$ rating. In this experiment, CPU board of $0.2 \mathrm{~kg}$ was thermally decomposed in the reactor. Measurement of temperature evolution inside the furnace was performed. Result was depicted in Fig. 5. It should be noted that the plasma torch was fully emerged inside the furnace and the temperature probe was positioned at the reactor axis, $100 \mathrm{~mm}$ away from the nozzle.

It was evident that the reactor temperature increased at a rapid rate and leveled off around 1,200 and $1,100 \mathrm{~K}$ at 50 and $100 \mathrm{~mm}$, respectively. The temperatures at both locations were close but did not attain the maximum level reported previously in the

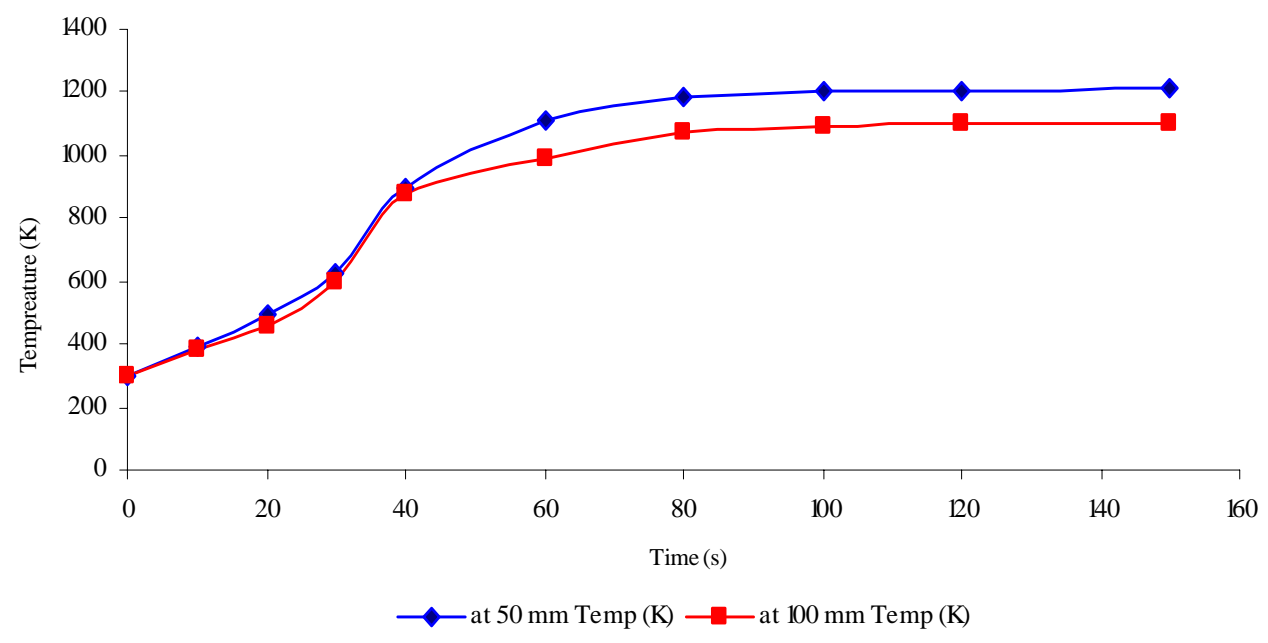

Fig. 5: Evolution of temperatures inside the furnace during plasma waste treatment

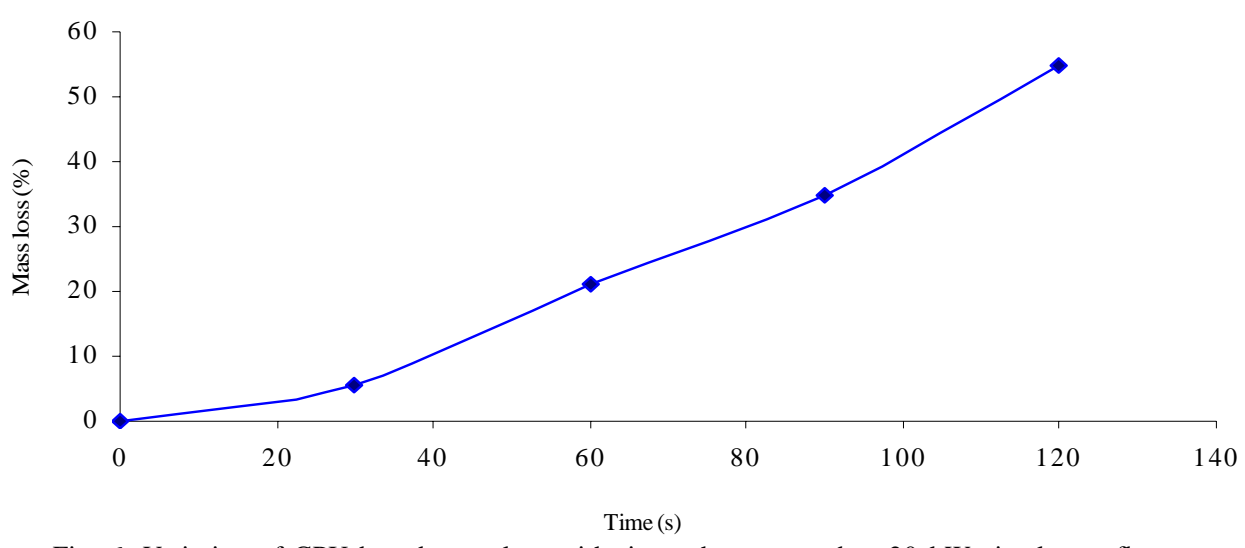

Fig. 6: Variation of CPU board mass loss with time when exposed to $20 \mathrm{~kW}$ air plasma flame 
naked plasma flame. This may be attributable to the fact that the plasma interacted with the waste and the plasma density decreased with distance. Nonetheless, a similar furnace temperature range to that reported by Vaidyanathan et al. (2007) was obtained in this study. Fig. 6 shows rate of mass reduction in the sample normalized by the initial mass when it was exposed to air plasma flame.

It can be seen that more than $50 \%$ of solid electronic waste was reduced in less than $120 \mathrm{~s}$ and the treatment was completely finished in about $150 \mathrm{~s}$. Most were rapidly converted to gases, while about $20 \%$ of the initial mass remained as solid residues. Change in physical appearance of the CPU board sample with time was illustrated in Fig. 7. It was clear that the air plasma can disintegrate, completely destroy and reduce volume of solid electronic waste. The remaining solid residues were inert materials that can be easily disposed of, or used as part of bulk material in road construction.

\section{Energy consumption and cost estimate}

One of the main reasons that restricts the wide adoption of plasma based technology is the cost of electrical energy involved. From the obtained results, the energy consumption required to drive the plasma torch to process waste material was about $3.0 \mathrm{MJ} / \mathrm{kg}$.

Table 1: Estimation of waste treatment costs for various methods (adapted from Tendler et al., 2005)

\begin{tabular}{lc}
\hline Treatment method & Cost (Euro/ton) \\
\hline Landfill burial & $105-160$ \\
Traditional incineration & $100-140$ \\
Pyrolysis/thermolysis & $90-150$ \\
Plasma without syngas utilization & $100-120$ \\
Plasma with syngas utilization & $70-90$ \\
\hline
\end{tabular}

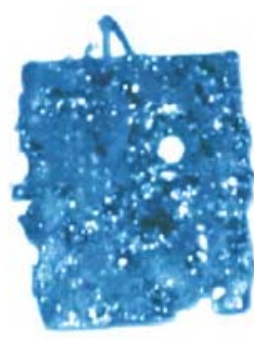

$30 \mathrm{~s}$

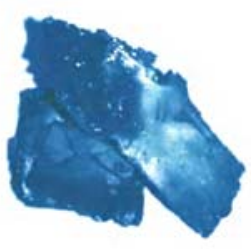

$60 \mathrm{~s}$

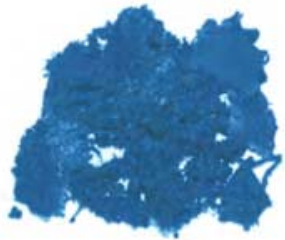

$90 \mathrm{~s}$

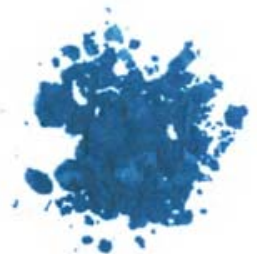

$120 \mathrm{~s}$

Fig. 7: Temporal change in physical appearance of CPU board after exposed to $20 \mathrm{~kW}$ air plasma flame 
Higher temperature can be achieved at higher power input, or addition of fuel gas, up to $1480 \mathrm{~K}$. A feasibility of the air plasma system for electronic waste treatment was demonstrated in a laboratory scale setup. It was observed that the air plasma system was able to achieve high temperature of $1200 \mathrm{~K}$ in about $80 \mathrm{~s}$ and promoted thermal decomposition and volume reduction of the waste to below $80 \%$ in just over two minutes. A number of trial runs demonstrated that the non-transferred DC air plasma was effective for the destruction of electronic wastes. Technically, plasma technology can be adopted as an alternative electronic waste treatment for fast operation and elimination of slag toxicity. However, electrical energy and cost of electricity involved are still the main obstacles towards utilization of the plasma waste treatment technology. The investigation of ways to improve the plasma torch performance and increase the efficiency of the process is very crucial.

\section{ACKNOWLEDGEMENTS}

Financial support from the Department of Mechanical Engineering, Chiang Mai University is acknowledged.

\section{REFERENCES}

Bang, C. U.; Hong, Y. C.; Cho, S. C.; Uhm, H. S.; Yi, W. J., (2006). Methane-augmented microwave plasma burner. IEEE T. Plasma Sci., 34 (5), 1751-1756 (6 pages).

Bonizzoni, G.; Vassallo, E., (2002). Plasma physics and technology; industrial applications. Vacuum, 64 (3-4), 327-336 (10 pages).

Chang, J. S., (2001). Recent development of plasma pollution control technology: a critical review. Sci. Tech. Adv. Mater., 2 (3-4), 571-576 (6 pages).

Ganguli, A.; Tarey, R. D., (2002). Understanding plasma sources. Curr. Sci., 83 (3), 279-290 (12 pages).

Gomez, E.; Amutha Rani, D.; Cheeseman, C. R.; Deegan, D.; Wise, M.; Boccaccini, A. R., (2009). Thermal plasma technology for the treatment of wastes: A critical review. J. Hazard. Mater., 161 (2-3), 614-626 (13 pages).

Hong, Y. C.; Cho, S. C.; Bang, C. U.; Shin, D. H.; Kim, J. H.; Uhm, H. S.; Yi, W. J., (2006). Microwave plasma burner and temperature measurements in its flames. Appl. Phys. Lett., 88 (20), 201502-201504 (3 pages).

Hsu, C. W.; Hu, A. H., (2008). Green supply chain management in the electronic industry. Int. J. Environ. Sci. Tech., 5 (2), 205-216 (12 pages).

Inaba, T.; Iwao, T., (2000). Treatment of waste by DC arc discharge plasmas. IEEE T. Dielect. El In., 7 (5), 684692 (9 pages).

Inaba, T.; Watanabe, Y.; Nagano, M.; Ishida, T.; Endo, M., (1998). Ar torch plasma characteristics and its application to waste treatment. Thin Solid Films, 316 (1-2), 111-116 (6 pages).
Kim, S. W.; Park, H. S.; Kim, H. J., (2003). 100 kW steam plasma process for treatment of PCBs (polychlorinated biphenyls) waste. Vacuum, 70 (1), 59-66 (8 pages).

Kogelschatz, U., (2004). Atmospheric pressure plasma technology. Plasma Phys. Contr. F., 46 (12B), B63-B75 (13 pages).

Leal-Quiros, E., (2004). Plasma processing of municipal solid waste. Braz. J. Phys., 34 (4B), 1587-1593 (7 pages).

Mishra, D. P.; Rahman, A., (2003). An experimental study of flammability limits of LPG/air mixtures. Fuel, 82 (7), 863-866 (4 pages).

Moustakas, K.; Fatta, D.; Malamis, S.; Haralambous, K.; Loizidou, M., (2005). Demonstration plasma gasification/ vitrification system for effective hazardous waste treatment. J. Hazard. Mater., 123 (1-3), 120-126 (7 pages).

Moustakas, K.; Xydis, G.; Malamis, S.; Haralambous, K.; Loizidou, M., (2008). Analysis of results from the operation of a pilot plasma gasification/vitrification unit for optimizing its performance. J. Hazard. Mater., 151 (2-3), 473-480 (8 pages).

Nnorom, I. C.; Osibanjo, O., (2008). Overview of electronic waste (e-waste) management practices and legislations, and their poor applications in the developing countries. Resour. Conser. Recycl., 52 (6), 843-858 (16 pages).

Park, H. S.; Lee, B. J.; Kim, S. J., (2005). Medical waste treatment using plasma. J. Ind. Eng. Chem., 11 (3), 353360 (8 pages).

Pfender, E., (1999). Thermal plasma technology: Where do we stand and where are we going? Plasma Chem. Plasma Proc., 19 (1), 1-31 (31 pages).

Shekdar, A. V., (2009). Sustainable solid waste management: An integrated approach for Asian countries. Waste Manage., 29 (4), 1438-1448 (11 pages).

Tang, L.; Huang, H., (2005). Biomass gasification using capacitively coupled RF plasma technology. Fuel, 84 (16), 2055-2063 (9 pages).

Tendler, M.; Rutberg, P.; van Oost, G., (2005). Plasma based waste treatment and energy production. Plasma Phys. Contr. F., 47 (5A), A219-A230 (12 pages).

Uhm, H. S.; Hong, S. H., (2000). Simple model of the plasma torch developed for application to an arc-plasma waste treatment system. Combust. Sci. Tech., 152 (1), 147 165 (19 pages).

Vaidyanathan, A.; Mulholland, J.; Ryu, J.; Smith, M. S.; Circeo, Jr. L. J., (2007). Characterization of fuel gas products from the treatment of solid waste streams with a plasma arc torch. J. Environ. Manage., 82 (1), 77-82 (6 pages).

Venkatramani, N., (2002). Industrial plasma torches and applications. Curr. Sci., 83 (3), 254-262 (9 pages).

Wald, S.; Glocker, B.; Weiss, E.; Pokryvailo, A.; Labrune, P.; Kempenaers, P.; Handte, J., (2001). Thermal pulsedplasma technology for hazardous waste treatment. Pulsed Power Plasma Sci., 1 (1), 620-623 (4 pages).

Wang, Q.; Yan, J.; Tu, X.; Chi, Y.; Li, X.; Lu, S.; Cen, K., (2009). Thermal treatment of municipal solid waste incinerator fly ash using DC double arc argon plasma. Fuel, 88 (5), 955-958 (4 pages). 
Widmer, R.; Oswald-Krapf, H.; Sinha-Khetriwal, D.; Schnellmann, M.; Boni, H., (2005). Global perspectives on e-waste. Environ. Impact Assess. Rev., 25 (5), 436 458 (23 pages).
Zhu, T.; Li, J.; Jin, Y.; Liang, Y.; Ma, G., (2008). Decomposition of benzene by non-thermal plasma processing: Photocatalyst and ozone effect. Int. J. Environ. Sci. Tech., 5 (3), 375-384 (10 pages).

\section{AUTHOR (S) BIOSKETCHES}

Tippayawong, N., Ph.D. from Imperial College, London, UK and an assistant professor in the Department of Mechanical Engineering, Chiang Mai University, Chiang Mai, Thailand. Email: n.tippayawong@yahoo.com

Khongkrapan, P., M.Eng., Research engineer in the Department of Mechanical Engineering, Chiang Mai University, Chiang Mai, Thailand. Email:ame196@hotmail.com

This article should be referenced as follows:

Tippayawong, N.; Khongkrapan, P., (2009). Development of a laboratory scale air plasma torch and its application to electronic waste treatment. Int. J. Environ. Sci. Tech., 6 (3), 407-414. 